\title{
EFFECT OF N'- NITROSONORNICOTINE (NNN) ON THE PALATAL FUSION IN MICE AND THE ROLE OF TRANSFORMING GROWTH FACTOR
}

\author{
Khaled A. Hussein* and Atef I. Ahmed**
}

\begin{abstract}
Background: Maternal smoking has been linked to an increased risk for orofacial clefts. $N^{\prime}$ nitrosonornicotine (NNN) is one of the tobacco specific nitrosamines that has been showed to be linked to the deleterious effects of tobacco and could linked to the formation cleft birth defects.

Objectivel: The aim of the present study was to evaluate the effects of $N$ '- nitrosonornicotine $(\mathrm{NNN})$ on palatal fusion in mice and the role of transforming growth factor $\alpha$ during palatogenesis.

Methodology: Adult C57BL/6J mice of 7-12 weeks old and weighing about 20-35 g were utilized in this experiment. Females were mated overnight with males. Twenty four pregnant mice were divided into two equal groups, group I, a control group $(n=10)$, which received dimethylsulphoxide (DMSO) and group II, an experimental group $(\mathrm{n}=10)$, which received $N$ '- nitrosonornicotine (NNN) dissolved in dimethylsulphoxide (DMSO). Histological and immunohistochemical effects of NNN on the palatogenesis of mice prenatally were evaluated.
\end{abstract}

Results: The results demonstrated that administration of NNN inhibit fusion of the palatal processes in mice.

Conclusion: There is a tight regulatory relationship between the TGF $\alpha$ and the normal palate development.

\section{INTRODUCTION}

The mammalian palate develops from the primary palate and the palatal shelves. The primary palate is derived from the frontonasal process, whereas the palatal shelves extend bilaterally from the internal surfaces of the maxillary processes, which will give rise to the hard palate in the anterior and the soft palate in the posterior. Elevation and fusion of the palatal shelves are two major events for palatogenesis. Perturbation of any step of palatogenesis can cause cleft palate, one of the most frequent congenital birth defects in the human population. A large number of the cleft palate cases involve the soft palate and submucous cleft. ${ }^{(1,2)}$

* Assistant Professor, Department of Oral and Dental Pathology, Faculty of Dental Medicine, Al-Azhar University, Assiut, Egypt.

** Lecturer, Department of Oral and Dental Biology, Faculty of Dental Medicine, Al-Azhar University, Assiut, Egypt. 
The incidence of palatal clefts is about $1 / 500$ to $1 / 1000$ live births worldwide. ${ }^{(3)}$ Causes of cleft palate are complex, with multiple genetic and environmental factors.Genetic factors contributing to cleft palate formation have been identified for some syndromic cases. Accordingly, Orofacial clefts have also been categorized into syndromic and non-syndromic clefts. The majority of clefts, almost $70 \%$ are regarded as non-syndromic. ${ }^{(4)}$ More than 300 syndromes have been described in which an orofacial cleft is part of the disorder as Van der Woude syndrome, Siderius X-linked mental retardation syndrome, Loeys-Dietz syndrome, Hardikar syndrome and Patau syndrome. . $^{(6)}$

In the mouse embryo, palate shelves grow and elevate into a horizontal position by postcoital day 14 (E14). The two palatal shelves fuse in the midline and extend anteriorly to fuse with the primary palate and nasal septum. The medial edge epithelia (MEE) of the opposing palatal shelves form the midline epithelial seam (MES), which eventually disappears following palate fusion. ${ }^{(7-9)}$

It is generally accepted that exposure to nicotine has adverse effects on fetal development. Higher mortality rates and lower birth weights are associated with maternal smoking during pregnancy. (10-12) Animal studies have shown that nicotine administration during pregnancy resulted in delayed implantation and decreased fetal weight, ${ }^{(13)}$ abnormal incisor and molar formation, ${ }^{(14,15)}$ and delayed tongue development. ${ }^{(16)}$ Maternal cigarette smoking as a risk factor for cleft palate has been demonstrated. ${ }^{(17-19)}$ In addition, fetal cleft palates can be induced in goats by maternal gavage of nicotinana glauca. ${ }^{(20-21)}$ Cleft palate was also induced in mice by daily maternal nicotine hemisulfate injections from gestational days 6-15. ${ }^{(22)}$ Epidemiological studies have established a significant positive correlation between maternal smoking and an increased risk for orofacial clefts in humans. ${ }^{(23,24)}$ Studies in mice have also shown that cleft palate can result from exposure in utero to tobacco smoke. ${ }^{(25)}$
Tobacco-specific nitrosamines are a group of carcinogens found only in tobacco products. They are formed by nitrosation of nicotine and related tobacco alkaloids. Seven tobacco-specific nitrosamines NNN, NNK, NNAL, NAT, NAB, iso-NNAL, and iso-NNAC- have been identified in tobacco products. ${ }^{(26)} \mathrm{NNN}, \mathrm{NNK}$, and NAT generally occur in quantities greater than the others. NNN, NNK, and NNAL are clearly the most carcinogenic of these compounds. Daily exposure to tobacco-specific nitrosamines is estimated at up to $20 \mathrm{mg}$ in smokers and $68 \mathrm{mg}$ in snuff-dippers. The exposure of nonsmokers to NNK has been confirmed by quantitation of its metabolites in the urine of people exposed to environmental tobacco smoke. Although uptake of NNK in non-smokers exposed to environmental tobacco smoke was only one-seventieth that of smokers, the potential for widespread exposure of both smokers and non-smokers to these compounds has been demonstrated. Consequently, tobacco specific nitrosamines can contribute to background DNA adduct formation. ${ }^{(27)}$

Growth factors are proteins that bind to receptors on the cell surface, with the primary result of activating cellular proliferation and/or differentiation. Many growth factors are quite versatile, stimulating cellular division in numerous different cell types; while others are specific to a particular cell-type. Many biological agents regulate epithelial mesenchymal transformation (EMT) during palate development. There are numerous experiments that support the hypothesis that transforming growth factor (TGF) $\beta 3$ contributes to palatal fusion. ${ }^{(27-31)} \mathrm{Tgf} \beta 3$ and type II Tgf $\beta$ receptors (T $\beta$ R-II) are localized in the middle edge epithelium (MEE) before fusion ${ }^{(32)}$. Tgf $\beta 3$ transgenic and knockout mice have cleft palate as their only craniofacial birth defect. ${ }^{(28-29)}$ When palatal shelves from Tgf $\beta 3$ knockout mice were cultured, the midline epithelia failed to go through EMT. ${ }^{(30)}$ The addition of TGF $\beta 3$ into culture media rescued the fusion of the palates from Tgf $\beta 3$-null mice. ${ }^{(31)}$ Interestingly, although chickens have natu- 
rally open palates, the cultured palatal shelves fused when TGF $\beta 3$ was added into the media. ${ }^{(33)}$

During fetal development TGF-alpha is expressed in numerous organs including the palate. On studying the distribution of transforming growth factor and the transforming growth factor receptors during palatal fusion immunocytochemically on different embryonic days, some authors found that regional and temporal differences in staining for the transforming and epidermal growth factor receptors suggested that these molecules may play an important role in normal palate development in vivo, particularly in degeneration of the midline epithelial seam. ${ }^{(34,35)}$

The present study was designed to determine the effects of NNN on the palatal fusion of mice prenatally and to evaluate the transforming growth factor receptor (TGFR) in the cell membrane of middle epithelial seam by its monoclonal antibody.

\section{MATERIALS AND METHODS}

Chemicals: $N^{\prime}$ - nitrosonornicotine (NNN) (Toronto Research Chemical Inc. Ontario, Canada)), $\mathrm{NNN}$ is greater than $95 \%$ pure, as determined by high performance liquid chromatography on $\mathrm{C} 18-\mu$ Bondapak reverse phase column. Dimethylsulphoxide (DMSO) (Sigma, St. Louis, MO) and chloroform were also used in this study.

Animals: Mouse strain C57BL/6J was used. Virgin females, 7-12 weeks old and weighing about 20$35 \mathrm{~g}$, were mated overnight with males of known fertility. The presence of a vaginal plug the following morning signified the day 0 of pregnancy. The pregnant mice were housed singly in metallic cages at constant temperature $\left(22-24^{\circ} \mathrm{c}\right)$ with $12 / 12$ light/ dark cycle and humidity (30-50\%). They had free access to stock laboratory food ad libitum with tap water.

Treatment: Twenty pregnant mice were divided into two groups. The first group (control group) in- cluded 10 pregnant mice was administered dimethylsulphoxide (DMSO) in a single dose at $10^{\text {th }}$ day of gestation then sacrificed by chloroform inhalation at the $17^{\text {th }}$ day of gestation. The second group (experimental group) included 10 pregnant mice that injected with $400 \mathrm{mg} / \mathrm{kg}(1.95 \mathrm{mM}) \mathrm{N}$ '- nitrosonornicotine (NNN) dissolved in DMSO in a single intraperitoneal dose at $10^{\text {th }}$ gestational day then sacrificed by chloroform inhalation at the $17^{\text {th }}$ day of gestation. The fetuses were aseptically removed from the uterine horns.

\section{Tissue preparation and staining procedures:} The heads of all fetuses were fixed in Bouin's solution for three days. The fixed tissues were washed, dehydrated, and then cleared. The cleared tissue were then infiltrated by molten paraffin wax and constructed in a sliding microtome. Coronal tissue sections of 5-6 $\mu \mathrm{m}$ thickness were cut. The tissue sections were then stained by hematoxylin and eosin (H\&E) for histological examination. The immune-histochemical examination was performed by evaluating the concentration of antigen within tissue for estimating the relative intensity of a chromogen label of TGFR. Some sections were covered with non-immune protein blocking serum, incubated with biotylinated secondary antibody and streptavidin enzyme. Coronal tissue sections of $5 \mu \mathrm{m}$ thickness were mounted on an electrically charged slide. Deparaffinization and rehydration of the tissue sections were performed in order to be ready for application of blocking of endogenous peroxidase using $\mathrm{H}_{2} \mathrm{O}_{2}$ methanol. Enzymatic treatment was performed by putting the slides in a solution to enhance the reaction in hot oven for 1 hour. Tissue sections, after that, were covered with non-immune protein blocking serum in humidity chamber for 30 minutes (protein blocking). Two-three drops of the monoclonal mice primary antibody was applied, following by incubation in a humidity chamber for 1 hour at room temperature. After washing the slides with phosphate buffered saline (PBS), they were incubated with biotylinated secondary antibody in humidity 
chamber for 30 minutes at room temperature. Tissue sections, after that, were incubated with streptavidin enzyme in humidity chamber for 30 minutes at room temperature. The transforming growth factor (TGF) receptor in the cell membrane of MEE was evaluated by its monoclonal antibody (Golden Lab, USA) using streptavidin biotin method. Diaminobenzidine (DAB) was applied to develop color. Tissue sections, after that, were counterstained with Mayer's hematoxylin for 30-40 seconds in order to be ready for microscopic examination. The examination was performed by evaluating the concentration of antigen within tissue for estimating the relative intensity of a chromogen label of TGFR.

Statistical analysis: Statical analysis of the obtained results was done according to (Snedcor and cochran, 1980). ${ }^{(36)}$ The frequencies of cleft palate in the experimental and control groups were collected and statistically analyzed. Statistical analysis of recorded data of both groups was done using X2 test to determine the significant relationship $(\mathrm{P}=0)$ between NNN administration and frequency of cleft palate induction.

\section{RESULTS}

In the Toxicity assay, no maternal death occurred in control and experimental group during the investigation period. The pregnant mice were in good health and free from signs of any diseases. However, three adult female animals died within 2-3 days. In addition, two animals were sick for a short time (vomiting) but recovered. The remaining rats did not show any toxic effects. Statistical analysis of data of both control group and NNN-treated group (Tab.1) indicate that, there was a highly significant relationship between the NNN administration and frequency of cleft palate induction (Fig. 1).

Histological examination of secondary palate of control group which were given DMSO and sacrificed at $17^{\text {th }}$ gestational day showed that no cleft occurred in all fetuses or offspring. The palatine shelves were in a horizontal position, well developed, and fused completely with each other. At the area of fusion, the epithelial seam was completely degenerated with no epithelial remnant. The histological examination of the experimental group was given $\mathrm{NNN}$ on $10^{\text {th }}$ of gestation and sacrificed at $17^{\text {th }}$ gestational day demonstrated a variety of histologic appearance. Some of them were completely bilaterally clefted, while the others were unilaterally clefted. In bilateral clefts many of them demonstrated horizontally directed under developed palatine shelves lied lateral to the highly positioned tongue, the tongue was reached to the nasal septum. In other cases, the palatine shelves were underdeveloped, one of them was directed vertically and the other was directed horizontally and both fail to reach to the midline. In unilateral clefts, the palatine shelves were directed horizontally, one of them was fused with the primary palate and nasal septum, while the other fail to reach to the midline. The epithelium covering the palatine shelves of bilateral cleft and

TABLE (1) Effect of NNN administration on the frequency of cleft palate

\begin{tabular}{|c|c|c|}
\hline & Control group & NNN treated group \\
\hline Total number of fetuses & 20 & 20 \\
\hline Fetuses with cleft palate & $0 \quad(0 \%)$ & $15(75 \%)$ \\
\hline Fetuses with complete palatal closure & $20 \quad(100 \%)$ & $3(15 \%)$ \\
\hline Fetuses with palatine closure with persistence of medial epithelial seam & $0 \quad(0 \%)$ & $2(10 \%)$ \\
\hline
\end{tabular}

$X 2=32.21 * * \quad P=0$

**Means the value showed highly significant relationship 


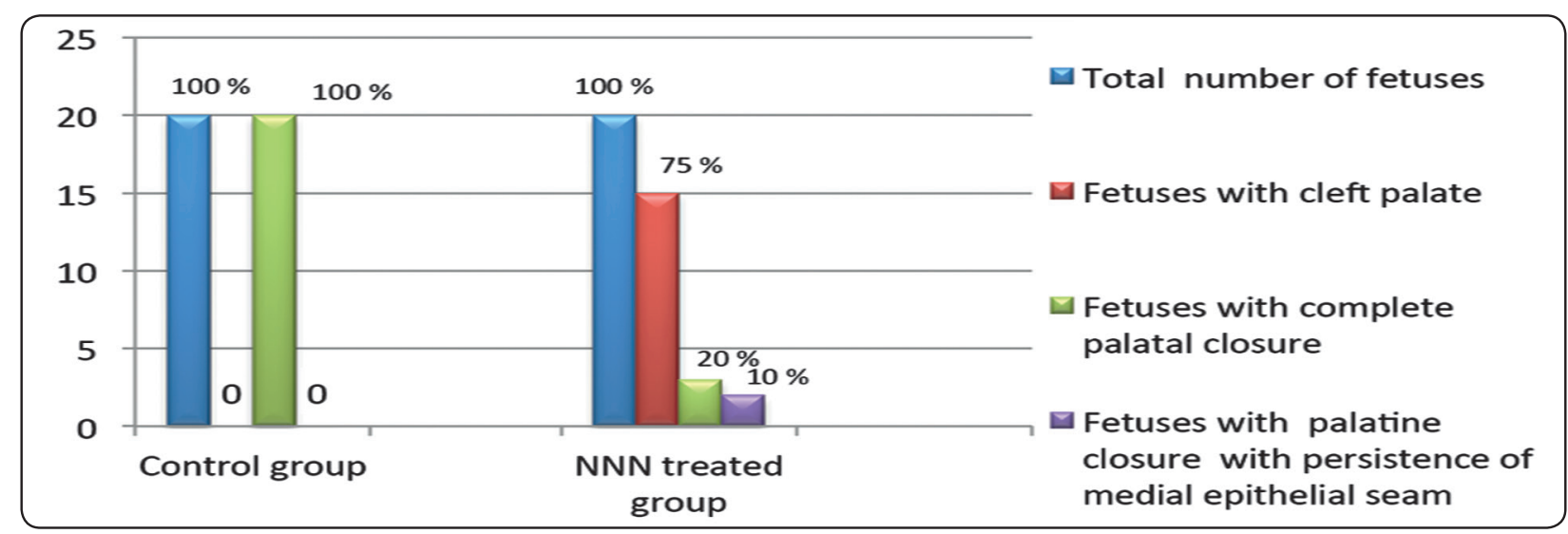

Fig. (1) Show percentage of cleft palate in both groups.

un-fused shelf of unilateral one was intact and the basement membrane retained its structural integrity. The underlining mesenchymal tissue of the shelves was not condensed by mesenchymal cells that seen in control group (Figs.2, 3). On other hand, the histological examination of this group revealed that, some fetuses have a complete palatal closure in which the palatine shelves were in a horizontal position and well developed. These shelves fused completely with each other medially (Tab.1).

The examination of immunohistochemically stained slides of the control and experimental group (NNN administered group) revealed different

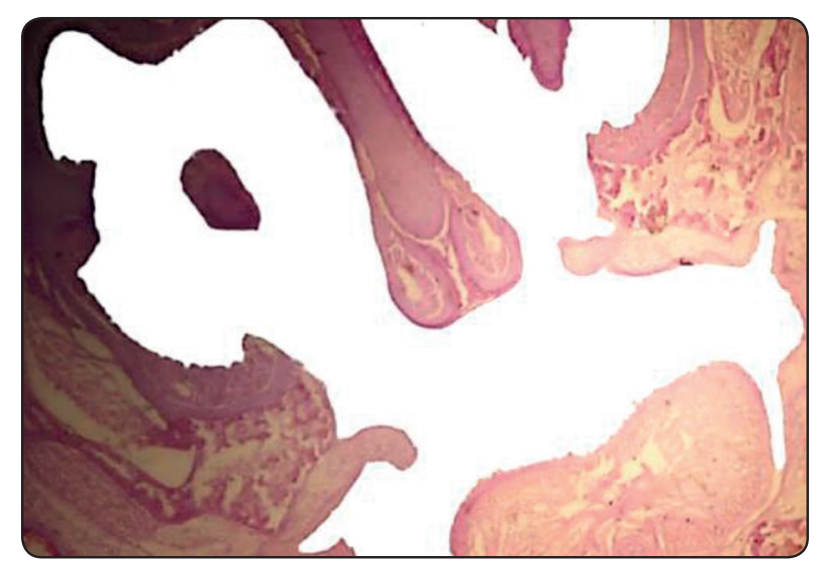

Fig. (2) Photomicrograph of coronal section of NNN-treated group of the palate, showing: bilateral cleft palate with horizontally positioned and underdeveloped palatal shelves. (H\&E., X 100). immuno-expression of TGF $\alpha$. In the control group, the immune-expression of TGF $\alpha$ was high in the epithelium and less intense in the mesenchyme. Both epithelial and mesencymal compartments show extensive proliferation (Figs. 4-6). But, in the experimental group the expression of TGF $\alpha$ was faint compared to the control group in the palatal epithelium and nearly absent in the mesenchymal cells and ossifying centers and epithelial seam cells. The mesenchyme showed a dramatic decrease of the proliferative activity. In some specimens immunoabelling for TGF $\alpha$ continuous to be seen in the isolated epithelia islands (Figs. 7,8).

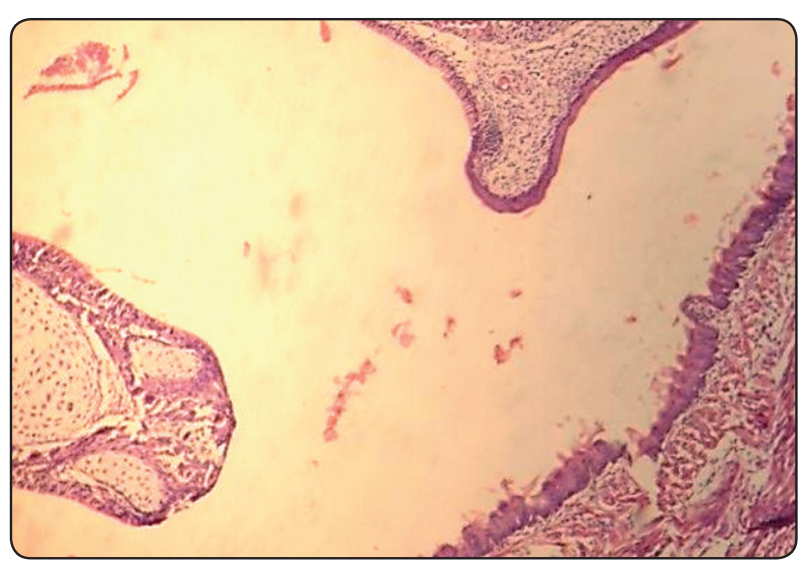

Fig. (3) Photomicrograph of coronal section of NNN treated group showing: unilateral cleft palate with under developed palatal shelf. (H\&E., X 200). 


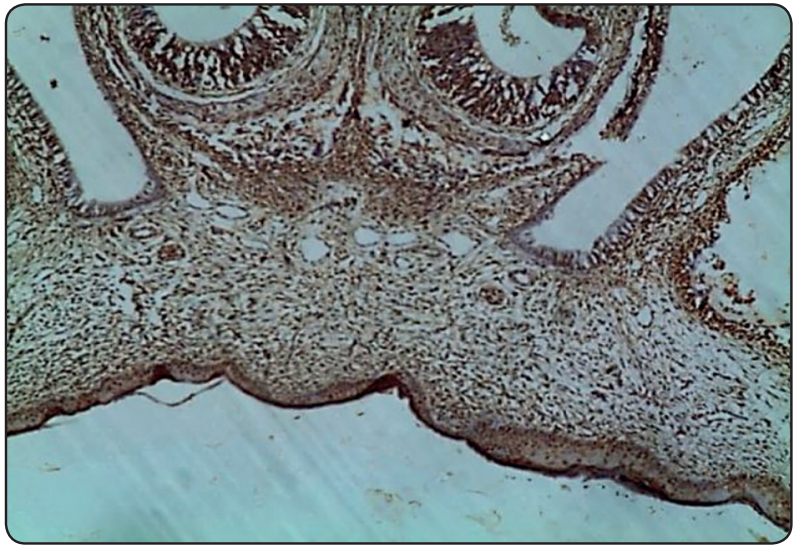

Fig. (4) Photomicrograph of coronal section at the middle third of the palate of the control group, showing: expression of TGF in the superficial layer of the palatal epithelium. (TGF $\alpha$ X200).

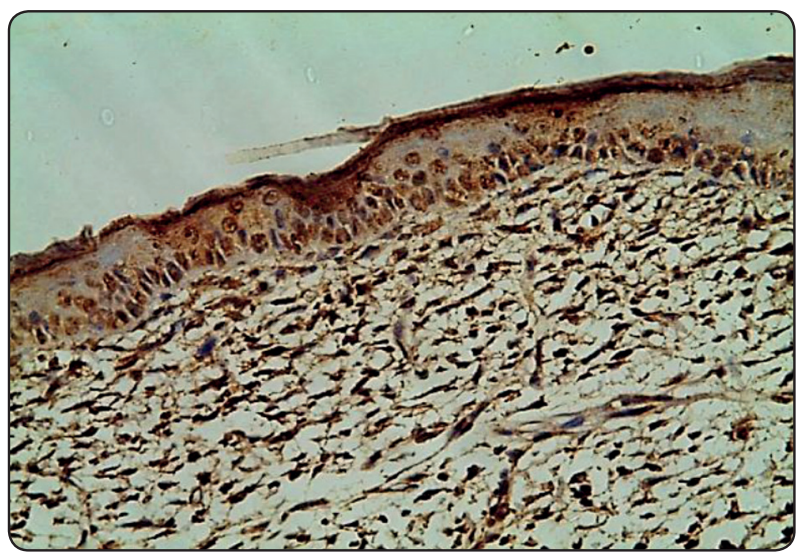

Fig. (6) Photomicrograph of coronal section at the middle third of the palate of the control group, showing: Expression of TGF in the superficial layer of the palatal epithelium and mesenchymal compartment. (TGF X 400).

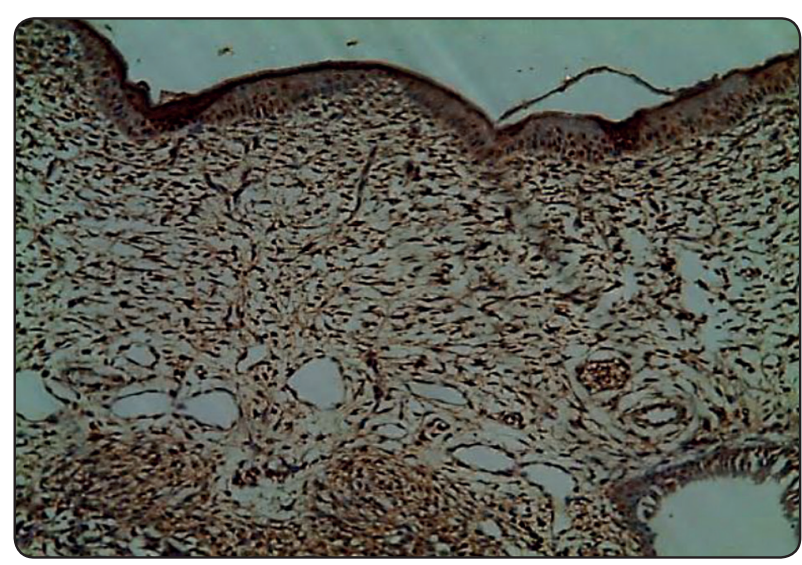

Fig. (5) Photomicrograph of coronal section at the middle third of the palate of the control group, showing: Expression of TGF in the superficial layer of the palatal epithelium and mesenchymal compartment. (TGF X200).

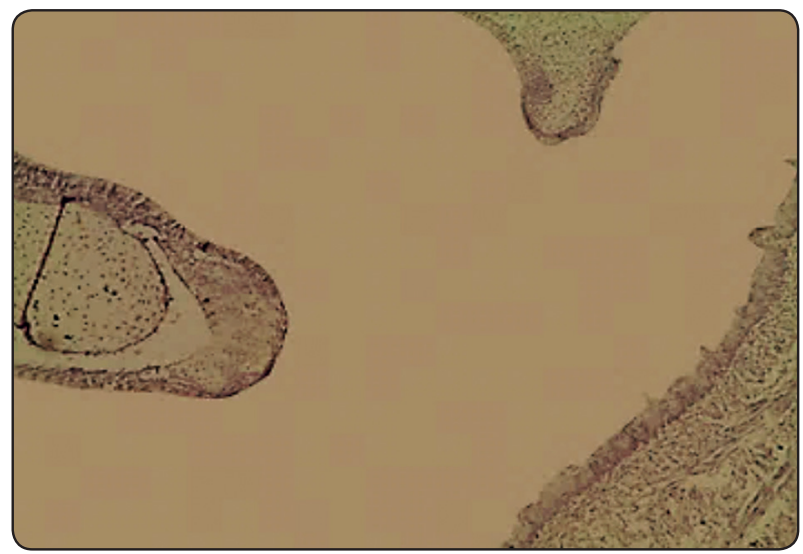

Fig. (7) Photomicrograph of experimental group (NNN treated group), showing: faint reaction to TGF in the palatal epithelium and mesencymal compartments with less proliferative activity. (TGF X 200)

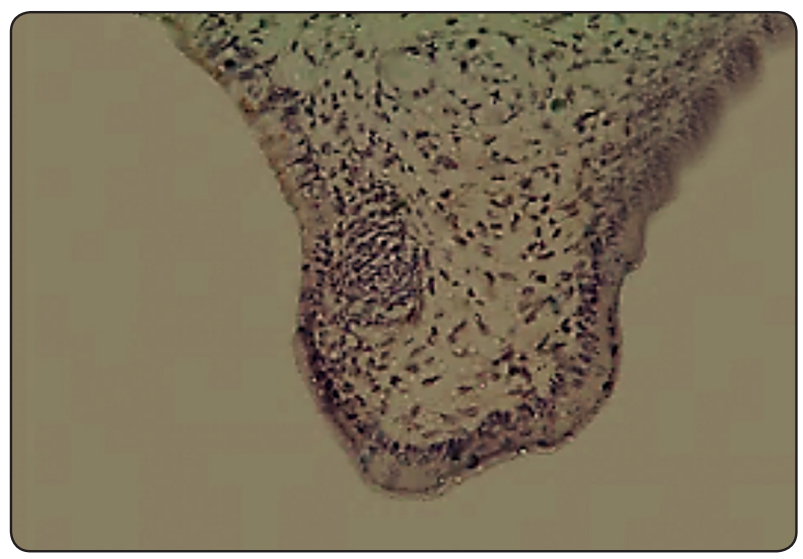

Fig. (8) Photomicrograph of experimental group (NNN treated group), showing: faint reaction to TGF in the palatal epithelium and mesencymal compartments with less proliferative activity. (TGF X 400) 


\section{DISCUSSION}

Orofacial clefting is a commonly reported congenital anomaly, and is therefore of considerable clinical importance. Cleft palate is also important because of their conspicuousness, as well as their attendant effects on speech, hearing and psychological well-being.

In this study the data in table 1 demonstrated that in the NNN administered group 15 fetuses with cleft palate $(75 \%)$. On other hand, the spontaneous palatal clefts in the control group were $(0 \%)$. The epithelial seam of the control group was completely degenerated and no epithelial remnant observed at the site of fusion of palatal shelves. The epithelial lining of both oral and nasal sides is of normal thickness and integrity. The mesenchymal tissue appeared condensed with normal behavior of calcification.

The present work showed that NNN affect the normal palate development. Maternal administration of NNN affects the growth, elevation of the palatal shelves into horizontal position, adhesion and fusion of the opposing palatal shelves leading to cleft palate. These results were in agreement with the observations of many authors. ${ }^{(23-25)}$

Most of cleft palate fetuses or offsprings showed under developed palatal shelves and this may related to inhibition of proliferation and growth of both epithelial and mesenchymal tissues. This finding was parallel to that reported by ${ }^{(22)}$ who reported that NNN inhibit the palatal shelves initiation and growth. Additionally, ${ }^{26,27)}$ reported that prenatal NNN exposure affects the regional accumulation and hydration of mucopolysaccharides, mainly hyaluronic acid, which provides an intrinsic shelf force essential to move the palatal shelf into horizontal position above the dorsum surface of the tongue.

In addition to the previous findings the histological examination showed that, there were vertically directed palatine shelves instead of horizontally positioned one in many fetuses and offsprings which might be related to failure of tongue drooping during mandibular development. This finding was coincidentally with Taya et al., 1999. ${ }^{(37)}$ Failure of dropping of the tongue indicates that NNN not only affect the palatal development but might interfere with normal tongue and mandible development and growth. Gato A. 2002 ${ }^{(38)}$ \& Tudela C. $2002{ }^{(39)}$ reported that NNN also affect the adherence and fusion between the palatal shelves by affecting the cell adhesion molecules, desmosomal components and growth factors essential for initial adhesion of palatal shelves, increasing the surface area of medial edge epithelium through induction of cellular bulges and filopodia and promoting degeneration of medial edge epithelium. Yamamoto $2003{ }^{(40)}$ reported that the medial edge epithelial (MEE) cells must stop DNA synthesis prior to the initial contact of opposing palatal shelves, otherwise, programmed cell death of MEE cells were prevented leading to cleft palate.

The histological examination of fetuses and offsprings of NNN administered group revealed that the epithelial seam at the site of fusion was persisted with no signs of degeneration. This indicates that maternal NNN administration led to continued medial edge epithelium cells proliferation and decreased medial edge epithelium cells apoptosis and decreased epithelial mesenchymal transformation. This finding might interpreted by Shuler C.F. et al., $1991{ }^{(41)}$ who reported that, NNN not only induce cleft palate malformation but also interfere with the apoptotic process of the epithelial seam, and prevent the formation of lysosomes needed for apoptosis. In general, maternal smoking was retrieved as a risk factor only for cleft palate types while other authors found a smoking risk for both types of clefts. ${ }^{(42-45)}$

The effects of NNN and NNK are believed to be initiated by the formation of promutagenic DNAadducts from reactive metabolites (Hecht and 
Hoffmann, $1988{ }^{(46)}$; Hecht et al., 1993) ${ }^{(47)}$. It has been shown that the smoking of tobacco during pregnancy has the potential to cause craniofacial birth defects in humans (Chung et al., 2000 ${ }^{(48)}$; Little et al., 2004b) $)^{(49)}$ and mice (Seller and Bnait, 1995) ${ }^{(50)}$. In addition to smoking, nicotine exposure by other manners alters craniofacial development. Panter et al., 2000 ${ }^{(51)}$ showed that feeding leaves of Nicotiana glauca induced cleft palate in goats and sheep, and Winn $1998{ }^{(52)}$ reported an increased incidence of cleft palate after NNK treatment of CD -1 mice. Although numerous effects have been documented the mechanism of NNN induction of craniofacial malformation has not been determined. These results provide evidence that NNN specifically alters programs of cell proliferation and cell death in defined populations of palatal cells critical for completion of the normal process of palatogenesis.

Takashi et al., $2005{ }^{(53)}$ demonstrated that NNN inhibits the program for palatal fusion in organ culture by a direct effect on the MEE. NNN treatment results in maintenance of MEE in the midline seam through continued MEE cell proliferation and decreased MEE cell death. Molecular changes linked to either cell proliferation or cell death are altered by $\mathrm{NNN}$ in a manner consistent with the changes observed in the cells. These observations may be linked to the mechanisms associated with the increased incidence of craniofacial clefting in children born to mothers who smoke during pregnancy.

Yamamoto et al.2003 ${ }^{(40)}$ found that NNN at a concentration of $1 \mathrm{mM}$ led to continued MEE cell proliferation and decreased MEE cell apoptoses at critical stage of development. It has been shown that inhibiting the cessation of DNA synthesis in the MEE will lead to a cleft palate malformation These observations indicate that NNN must be affecting molecular mechanisms critical to DNA synthesis and cell proliferation. It was found that $1 \mathrm{mM} \mathrm{NNN}$ caused the greatest alteration of MEE cell fate. The typical concentrations of nitrosamine and nicotine used in monolayer cell culture model systems are in the range from100nM to $10 \mathrm{M}$ (Cucina et al., 2000). ${ }^{(54)}$

However, other authors have shown that the concentration of nicotine required to observe an effect in organ culture models was higher, requiring concentrations between 0.6 and $6 \mathrm{mM}$ to inhibit palatal fusion (Kang and Svoboda, 2003). ${ }^{(55)}$ These differences are probably due to differences in the permeability of chemicals between organ culture and monolayer cell culture models. Although the level of NNN has never been determined in smokers, there are 1000-10,000 fold lower levels of NNN in tobacco smoke when compared to nicotine (Roemer et al., 2004), ${ }^{(56)}$ thus it might be expected that only nanomolar concentrations would occur in smoker's blood, however levels of NNN have not been characterized in smokers or fetuses exposed to tobacco-smoke by products. While the NNN concentrations used in the present organ culture model might be higher than the level of NNN found in arterial blood from smokers, the effects of NNN distribution to tissues through the circulation and concentration of NNN in specific sites can not be replicated in this model.

From the immunohistochemical point of view, staining of the TGF $\alpha$ used in the present study showed a faint reaction in the palatal epithelium and medial epithelial seam of the experimental group. On other hand, the TGF was expressed in the palatal epithelium of the control group. TGFR was expressed strongly in palatal cells and in the mesenchyme cells. In treated palates, the expression of TGFR was maintained in this region and hyperproliferation was observed. TGF was observed to increase with gestational age in palatal cells and expression declined in response to NNN. Our results point to a tight regulatory relationship between the TGF and the normal palate development. The results obtained from this study proposed that slight shift in 
the TGF distribution could alter the normal medial edge epithelium apoptosis and differentiation with consequence inhibition of palatal fusion.

This study showed the immunolocalization of TGF $\alpha$ and its receptor throughout the palatal fusion processes as well as its association with cell proliferation and differentiation. TGF $\alpha$ and TGFR were highly expressed in epithelial cells and less intensely in the mesenchymal tissue of palatal shelf. As the epithelial seam degenerated there was a general increase in epithelial staining for TGF $\alpha$ and TGFR, particularly in the seam remnants. Proliferative activity was very high in both the mesenchyme and the epithelia during early palatal development. It gradually decreased in mesenchyme, whereas it persisted in oral and nasal epithelia. TGF $\alpha$ has been shown to be mitogenic for a variety of epithelia and other tissues. In addition, $\mathrm{TGF} \alpha$ is capable at promoting not only epithelial cell growth but also cell differentiation (Helene et al., 1994). ${ }^{(57)}$ The growth and differentiation of the oral, nasal and MEE are probably very dependent upon $\mathrm{TGF} \ll$ and its receptor.

The present findings may be correlated with Xun Xu et al., $2006{ }^{(58)}$ who showed that epithelialmesenchymal transformation does not occur in the process of palatal fusion. TGF- $\beta$ IIR plays a crucial, cell autonomous role in regulating the fate of MEE during palatogenesis. Future studies using this animal model will provide important information on the molecular mechanism of TGF- $\beta$ signaling in regulating normal and abnormal palatogenesis. Genetic screening of TGF-BR2 mutation among individuals with soft palate cleft and submucous cleft may provide crucial information in linkage analysis to investigate the etiology of congenital malformations

During palatal fusion, several growth factors have been reported to influence the complex events during palatogenesis. Components of the EGF and transforming growth factor (TGF) signaling pathways may interact in controlling palatal cell proliferation and differentiation. The MEE was maintained in a proliferative state following EGFinduced nuclear ERK1/2 activation and palatal fusion was inhibited. The cytoplasmic ERK1/2 activation in the MEE during normal palatal fusion might play a crucial role in cellular differentiation critical to complete palatal fusion (Yamamoto et al., 2003) ${ }^{(40)}$ The EGF receptor (EGFR) may be involved in nicotine-induced phosphorylation of ERK and Akt (Nakayama et al.,2001,2002). ${ }^{(59,60)}$

Thus the current observations of the effect of NNN on palatal fusion may occur through an TGF-related mechanism that affects MEE cell proliferation. An alternative mechanism may be explained through effects on the TGF pathway. Nicotine treatment caused down regulation of phoshatidylinositol-3 kinase that is an alternative downstream signal in the TGF pathway and this change was linked to inhibiting palatal fusion in vitro (Kang and Svoboda, 2003). ${ }^{(55)}$ Since the TGF pathway is critical to normal palatal fusion, NNN could alter these pathways resulting in a developmental end point that resembles the effects of null mutations of TGF (Cui et al., 2003) (61) NNN can bind to nicotinic acetylcholine receptors (nAchR) in a manner that is similar to nicotine. AChRs exist on palatal epithelium as well as on the other epithelium. Apoptosis reduction by nicotine or nitrosamines has been correlated with the AChRs on lung cancer cells (Minna, 2003). ${ }^{(62)}$ Therefore, the effect of NNN may be to activate and reduce MAP kinases through AChRs in MEE. This hypothesis is further supported by the observation that nicotine can inhibit palatal fusion by binding to a neuronal nAchR (Kang and Svoboda, 2003). ${ }^{(55)}$

Additionally, this study demonstrated the presence of TGF throughout all the steps of fusion and with the same intensity of immunolabeling. 
Simultaneously, the epithelia facing the nasal and oral cavities differentiate respectively into pseudostratitied, ciliated columnar and stratified, squamous keratinizing epithelia Our study confirms that TGF $\alpha$ remains present in those epithelial cells. At the same time we also demonstrated a variation in the degree of epithelial cell proliferation. This may suggest that TGF $\alpha$ not only plays a role in cell growth, but interferes in other processes, such as cell differentiation.

These results were supported by Dixon et al. $1993^{(63)}$ was found that EGF and TGF $\alpha$ did not inhibit MEE degeneration in palatal shelves cultured under serum free conditions. These organ cultures under serum free conditions show additional interaction between many factors, e.g. TGF $\alpha$, EGF, platelet derived growth factor (PDGF) during MEE degeneration. An intense expression ot the basic fibroblast growth factor (FGF) in the MEE during seam formation as well as disruption was also reported. Sharpe ef al., $\mathbf{1 9 9 3}^{(64)} \&$ Sharpe et $\mathbf{a . , 1 9 9 2}{ }^{(65)}$ demonstrated that activity of EGF and TGF» in the developing mammalian palate may be modulated by endogenous growth factors at the EGF-R and post-receptor level.

Moreover, Dixon et al. $1993^{(63)}$ suggested that palatal MEE cells synthesized ECM molecules, e.g. tenascin, and that this synthesis could be stimulated by TGFa and serum. Physiological effects of TGF $\alpha$ during normal palatal development are likely to be the result of complex interactions between differing growth factors and ECM molecules at differing developmental times.

Finally, Regulation of growth and development is controlled by the interactions of cells with each other and the extracellular environment through signal transduction pathways that control the differentiation process by stimulating proliferation or causing cell death.

\section{REFERENCES}

1. Tolarová, M., Cervenka, J. Classification and birth prevalence of orofacial clefts. Am. J. Med. Genet. 1998; 75, 126-137.

2. Heliövaara, A., Ranta, R., Rautio, J. Pharyngeal morphology in children with submucous cleft palate with and without surgery. Eur. Arch. Otorhinolaryngol. 2005; $262,534-538$

3. Gritli-Linde A. Molecular control of secondary palate development. Dev Biol. 2007; 301:309-326.

4. Stanier P \& Moore GE. Genetics of cleft lip and palate: syndromic genes contribute to the incidence of nonsyndromic.2004;13:73-81.

5. Zucchero TM, Cooper ME, Maher BS, et al. Interferon Regulatory Factor 6 (IRF6) Gene Variants and the Risk of Isolated Cleft Lip or Palate New England Journal of Medicine. 2004; 351:769- 780.

6. Siderius LE, Hamel BC, van Bokhoven H, et al. "X linked mental retardation associated with cleft lip/palate map Xp11.3-q21.3”. Am.J.Med. Genet.2000; 85 (3):216-220.

7. Ferguson, M.W. Palate development. Development 1988;103, 41-60 (Suppl)

8. Shuler, C.F. Programmed cell death and cell transformation in craniofacial development. Crit. Rev. Oral Biol Med.1995; 6, 202-217.

9. Wilkie, A.O., Morriss-Kay, G.M. Genetics of craniofacial development and malformation. Nat. Rev., Genet. 2001; $2,458-468$.

10. Abel EL. Smoking during pregnancy: a review of effects on growth and development of offspring. Hum Biol 1980;52:593-625. [PubMed: 7009384]

11. Rowell, PP, Clark MJ. The effect of

12. chronic oral nicotine administration on fetal weight and placental amino acid accumulation in mice. Tox \& App Pharm 1982;66:30-8.

13. Tuthill, DP, Stewart JH, Coles EC, Andrews J, Cartlidge PH. Maternal cigarette smoking and pregnancy outcome. Paed \& Perinat Epidem 1999;13:245-53.

14. Seller, MJ., Bnait, KS.; Cairns, NJ. Effect of maternal tobacco smoke inhalation on early embryonic growth. In: Poswillo, D.; Alberman, E., editors. Effects of Smoking on the Fetus, Neonate and Child. Oxford: Oxford University Press; 1992. p. 45-59. 
15. Gartner LP, Saad AY, Hiatt JL. Effects of nicotine on murine incisor development. J Biol Buccale 1990;18:83-8. [PubMed: 2211582]

16. Saad, AY., Gartner LP, Hiatt JL. Teratogenic effects of nicotine on first molar odontogenesis in the mouse. Acta Morphol Hung 1991;39:87-96. [PubMed: 1789149]

17. Gartner, LP., Saad AY, Hiatt JL. Effects of nicotine on tongue development in the cd-1 mouse. Eur J Morphol 1997;35:337-43. [PubMed: 9455660]

18. Hwang, SJ. Association study of transforming growth factor alpha (TGF alpha) polymorphism and oral clefts: indication of gene-environment interaction in a populationbased sample of infants with birth defects. Amer J Epidem 1992;135:1000

19. Chung, KC., Kowalski CP, Kim HM, Buchman SR. Maternal cigarette smoking during pregnancy and the risk of having a child with cleft lip/palate. Plast Reconstr Surg 2000;105:485-91. [PubMed: 10697150]

20. Lorente, C., Cordier, S, Goujard, J, Ayme, S, Bianchi, F., Calzolari, E, et al. Tobacco and alcohol use during pregnancy and risk of oral clefts. Occupational exposure and congenital malformation working group. Am J Public Health 2000;90:415-9. [PubMed: 10705862]

21. Weinzweig, J., Panter, KE, Pantaloni, M, Spangenberger, A, Harper JS, Lui F, et al. The fetal cleft palate: I. Characterization of a congenital model. Plast Reconstr Surg 1999;103:419-28. [PubMed: 9950527]

22. Panter, KE., Weinzweig, J, Gardner, DR, Stegelmeier, BL, James, LF. Comparison of cleft palate induction by nicotiana glauca in goats and sheep. Teratology 2000;61:203-10. [PubMed: 10661910]

23. Saad AY, Gartner LP, Hiatt JL. Teratogenic effects of nicotine on palate formation in mice. Biol Struct Morph 1990;3:31-5.

24. Little, J., Cardy, A., Arslan, M.T., Gilmour, M., Mossey, P.A. Smoking and orofacial clefts: a United Kingdombased casecontrol study. Cleft Palate Craniofac. J. 2004a; 41, 381-386.

25. Little, J., Cardy, A., Munger, R.G. Tobacco smoking and oral clefts: a meta-analysis. Bull. World Health Organ. 2004b; 82, 213-218

26. Seller, M.J., Bnait, K.S. Effects of tobacco smoke inhalation on the developing mouse embryo and fetus. Reprod. Toxicol. 1995; 9, 449-459.
27. Hecht, S.S. Biochemistry, biology, and carcinogenicity of tobacco-specific N-nitrosamines, Chem. Res. Toxicol. 11.1998 559-603.

28. Parsons, WD.,Carmella, SG, Akerkar, S, Bonilla,LE,Hecht SS. A metabolite of the tobacco-specific lung carcinogen methylnitrosamino-1-3-pyridyl -1-butanone NNK in the urine of hospital workers exposed to environmental tobacco smoke, Cancer Epidemiol., Biomarkers and Prev., in. press 1998 .

29. Kaartinen, V., Voncken JW, Shuler C, Warburton D, Bu D, Heisterkamp N, et al. Abnormal lung development and cleft palate in mice lacking tgf-beta 3 indicates defects of epithelial-mesenchymal interaction. Nat Genet 1995;11:415-21. [PubMed: 7493022]

30. Proetzel, G., Pawlowski SA, Wiles MV, Yin M, Boivin GP, Howles PN, et al. Transforming growth factor- $\beta 3$ is required for secondary palate fusion. Nat Genet 1995;11:409-14. [PubMed: 7493021]

31. Kaartinen, V., Cui XM, Heisterkamp N, Groffen J, Shuler CF. Transforming growth factor-beta3 regulates transdifferentiation of medial edge epithelium during palatal fusion and associated degradation of the basement membrane. Dev Dyn 1997;209:255-60. [PubMed: 9215640]

32. Taya, Y., O'Kane S, Ferguson MW. Pathogenesis of cleft palate in tgf-beta3 knockout mice. Develop 1999; 126:3869-79.

33. Cui, XM., Warburton D, Zhao J, Crowe DL, Shuler CF. Immunohistochemical localization of tgf-beta type II receptor and tgf-beta3 during palatogenesis in vivo and in vitro. Int J Dev Biol 1998;42:817- [PubMed: 9727838]

34. Sun, D., Vanderburg CR, Odierna GS, Hay ED. TGF $\beta 3$ promotes transformation of chicken palate medial edge epithelium to mesenchyme in vitro. Develop 1998; 125:95-105.

35. Okey AB, Riddick DS, Harper PA. The Ah receptor: mediator of the toxicity of 2,3,7,8- tetrachlorodibenzo -p- dioxin (TCDD) and related compounds. Toxicol Lett. 1994; 70: 1-22.

36. Martinez-Alvarez C, Blanco MJ, Perez R, et al. Snail family members and cell survival in physiological and pathological cleft palates. Dev. Biol. 2004; 265: 207-218.

37. Snedeeor G. W and Cochran. W.G. Statistical Methods. Oxford and J.B.H. Publishing co, 1980; 6 th ed. 
38. Taya, Y., O'Kane S., Ferguson, MWJ. Pathogenesis of cleft palate in TGF- $\beta 3$ knockout mice. Development. 1999; 126: 3869-3879.

39. Gato, A., Martinez, ML, Tudela, C, et al. TGF- $\beta 3$ induced chondroitin sulphate proteoglycan mediates palatal shelf adhesion. Dev. Biol. 2002; 250: 393-405.

40. Tudela, C., Formoso MA, Martinez T, et al. TGF- $\beta 3$ is required for the adhesion and intercalation of medial edge epithelial cells during palate fusion. Int. J. Dev. Biol. 2002; 46: 333-336.

41. Yamamoto, T., Cui, X.M., Shuler, C.F. Role of ERK1/2 signaling during EGF-induced inhibition of palatal fusion. Dev. Biol. 2003; 260, 512-521.

42. Shuler, C., Halpern, DE, Guo, Y. and Sank, A.C. Medial edge epithelium fate traced by lineage analysis du ring epithelial. mesenchymal transformation in vivo. Dev. BioI. 1992; 154: 318.330 .

43. Ericson, A., Kallen B, Westerholm P. Cigarette smoking as an etiologic factor in cleft lip and palate. Am .I Obstet Gynecol. 1979; 51-135-348.

44. Khoury, MJ., Weinstein A, Panny S, Holtzman NA, Lindsay PK, Farrel K, Eisenberg M. Maternal cigarette smoking and oral clefts: a population study. Am J Public Health. 1987;77:623-5.

45. Shaw, G., Wasserman CR. Influence of maternal smoking, paternal smoking and involuntary maternal smoke exposures on oral cleft defects. Am J Epidemiol. 1993;138:596.

46. Long, S., Robert E, Laumon B, Pradat E, Robert JM. Epidemiologic des fentes labiales et palatines dans la region RhBne-Alpesl Auvergne/Jura. A propos de 903 cas enregistrts entre 1978 et 1987. Ptdiatrie. 1992; 47: 13340 .

47. Hecht, SS., Hoffmann, D. Tobacco-specific nitrosamines, an important group of carcinogens in tobacco and tobacco smoke. Carcinogenesis 1988; 9, 875-884.

48. Hecht, SS., Carmella, S.G., Foiles, P.G., Murphy, S.E., Peterson, L.A. Tobacco-specific nitrosamine adducts: studies in laboratory animals and humans. Environ. Health Perspect. 1993; 99, 57-63

49. Chung, KC., Kowalski, C.P., Kim, H.M., Buchman, S.R. Maternal cigarette smoking during pregnancy and the risk of having a child with cleft lip/palate. Plast. Reconstr. Surg. 2000; 105, 485-491.
50. Little, J., Cardy, A., Munger, R.G. Tobacco smoking and oralclefts: a meta-analysis. Bull. World Health Organ. 2004b; 82, 213-218.

51. Seller, M.J., Bnait, K.S. Effects of tobacco smoke inhalation on the developing mouse embryo and fetus. Reprod. Toxicol. 1995; 9, 449-459.

52. Panter, K.E., Weinzweig, J., Gardner, D.R., Stegelmeier, B.L., James, L.F. Comparison of cleft palate induction by Nicotiana glaucain goats and sheep. Teratology 2000; 61, $203-210$.

53. Winn, L.M. Investigation of the tobacco-specific carcinogen 4- methylnitrosamino)-1-(3-pyridyl)-1butanone for in vivo and in vitro murine embryopathy and embryonic ras mutations. J. Pharmacol. Exp. Ther. 1998; 287, 1128-1135

54. Takashi Saito, Xiao-Mei Cui, Tadashi Yamamoto, Nobuyuki Shiomi, Pablo Bringas Jr., Charles F. Shuler: Effect of $\mathrm{N}$-nitrosonornicotine (NNN) on murine palatal fusion in vitro. Toxicology 2005; 207 475-485.

55. Cucina, A., Sapienza, P., Corvino, V., Borrelli, V., Mariani, V., Randone, B., Santoro D'Angelo, L., Cavallaro, A. Nicotineinduced smooth muscle cell proliferation is mediated through FGF and TGF-beta 1. Surgery 2000; $127,316-322$

56. Kang, P., Svoboda, K.K. Nicotine inhibits palatal fusion and modulates nicotinic receptors and the PI-3 kinase pathway in medial edge epithelia. Orthod. Craniofac. Res. 2003; 6, 129-142

57. Roemer, E., Stabbert, R., Rustemeier, K., Veltel, D.J., Meisgen, T.J., Reinninghaus, W., Carchman, R.A., Gaworski, C.L., Podraza, K.F. Chemical composition, cytotoxicity and mutagenicity of smoke from US commercial and reference cigarettes smoked under two sets of machine smoking conditions. Toxicology 2004; 195, 31-52.

58. Helene, L., Citterio and Domoque A. Gaillard. Expression of transforming growth factor alpha (TGFa), epidermal growth factor receptor (EGF-R) and cell proliferation during human palatogenesis: an immunohistochemical study, Int. J. De.. BioI. 1994; 38: 499-505.

59. Xun Xu, Jun Han, Yoshihiro Ito, Pablo Bringas Jr., Mark M. Urata, Yang Chai. Cell autonomous requirement forTgfbr2in the disappearance of medial edge epithelium during palatal fusion. Developmental Biology 2006; 297, 238-248. 
60. Nakayama, H., Numakawa, T., Ikeuchi, T. Nicotineinduced phosphorylation of Akt through epidermal growth factor receptor and Src in PC12 h cells. J. Neurochem.2002; 83, 1372-1379.

61. Nakayama, H., Numakawa, T., Ikeuchi, T., Hatanaka, H. Nicotine-induced phosphorylation of extracellular signalregulated protein kinase and CREB in PC12 h cells. J. Neurochem.2001; 79, 489-498.

62. Cui, X.M., Chai, Y., Chen, J., Yamamoto, T., Ito, Y., Bringas, P., Shuler, C.F. TGF-beta3-dependent SMAD2 phosphorylation and inhibition of MEE proliferation during palatal fusion. Dev. Dyn. 2003; 227, 387-394.

63. Minna, J.D. Nicotine exposure and bronchial epithelial cell nicotinic acetylcholine receptor expression in the pathogenesis of lung cancer. J. Clin. Invest. 2003; 111, 31-33.
64. Dixon, MJ., Caretie, MJ., and Ferguson, M.W. Differentiation of isolated murine embryonic palatal epithelium in culture: exogenous transforming growth factor alpha modulates matrix biosynthesis in defined experimental conditions. In Vitro Cell. Dev. Bio. 1993; 29A:51-61

65. Sharpe, P.M., Brunet, C.1., Foreman, DM., and Ferguson, MW. Localization of acidic and basic fibroblast growth factors during mouse palate development and their effect on mouse palate mesenchyme cells in VItro. Roux Arch. Dev Brol. 1993, 202: 132-143.

66. Sharpe, P.M., Brunet, C.1., Foreman, DM., and Ferguson, MW. Modulation of the epidermal growth factor receptor of mouse embryonic palatal mesenchyme cells in vitro by growth factor. Int. J. Dev. Bio. 1992; 36: 275-282. 